\title{
NOTAS SOBRE AS DECISÕES DO COMITÊ DE DIREITOS HUMANOS DA ONU: DIREITO À FAMÍLIA LGBT
}

Felipe Sakai Souza ${ }^{1}$, Camila Soares Lippi ${ }^{2}$

Resumo: O presente artigo analisa as decisões do Comitê de Direitos Humanos da ONU relativas ao direito à família da população gay, lésbica, bi e transexual (LGBT) a partir da perspectiva teórica queer. Pretendeu-se compreender como o Comitê de Direitos Humanos, responsável pelo monitoramento do Pacto Internacional dos Direitos Civis e Políticos, de 1966, tem interpretado esse direito importante para o grupo em análise, perguntando até que ponto o órgão conseguiu realizar uma interpretação evolutiva. Constatouse que o mecanismo paulatinamente sinaliza para adoção de uma interpretação que tende a reconhecer a pluralidade das formas de constituir vínculos familiares.

Palavras-chave: Comitê de Direitos Humanos. Direitos à família. LGBT.

Abstract: This article analyzes the decisions of the UN Human Rights Committee regarding the right to the family of the gay, lesbian, bisexual and transgender (LGBT) population from the queer theoretical perspective. It was intended to understand how the Human Rights Committee, responsible for monitoring the International Covenant on Civil and Political Rights, of 1966, has interpreted this important right to the group under analysis, wondering to what extent it has been able to carry out an evolutionary interpretation. It was found that the mechanism gradually signals to adopting an interpretation that tends to recognize the plurality of forms of building family ties.

Keywords: Human Rights Committee. Rights to the family. LGBT.

\section{Introdução}

$\mathrm{O}$ presente artigo analisa as decisões do Comitê de Direitos Humanos (CDH), responsável pelo monitoramento do Pacto Internacional dos Direitos Civis e Políticos (PIDCP), de 1966, relativas ao direito à família da

${ }^{1}$ Graduando em Direito pela Universidade Federal do Amapá

${ }^{2}$ Universidade Federal do Amapá 
população gay, lésbica, bi e transexual (LGBT) a partir da perspectiva teórica queer, pacto ratificado por 170 Estados, inclusive o Brasil ${ }^{3}$.

Pretende-se compreender como o $\mathrm{CDH}$ tem interpretado esse direito importante para o grupo em análise, perguntando até que ponto o órgão conseguiu realizar uma interpretação evolutiva. Tal avaliação é relevante para responder à pergunta, se o sistema global constitui um espaço fértil para o sucessivo reconhecimento do direito à família LGBT.

Para melhor compreender $\mathrm{o}$ objeto deste trabalho, adotou-se o seguinte percurso analítico: em primeiro lugar, discutiu-se a orientação sexual a identidade de gênero no Direito Internacional; em seguida foi feita uma exposição dos casos decididos pelo Comitê; finalmente, analisaram-se essas sob o marco teórico queer.

\footnotetext{
${ }^{3}$ Decreto-presidencial $n^{\circ} 592$, de 6 de julho de 1992.

${ }^{4}$ Resolução 217 A (III) da Assembleia Geral da ONU, de 10 de dezembro de 1998.

${ }^{5}$ Convenção Internacional sobre Eliminação de todas as formas de Discriminação Racial; Pacto Internacional dos Direitos Civis e Políticos; Pacto Internacional dos Direitos Econômicos Sociais e Culturais; Convenção contra Tortura e outros Tratamentos ou Penas Cruéis, Desumanas
}

\section{Orientação Sexual e Identidade De} Gênero No Direito Internacional

Gênero e sexualidade têm sido, tradicionalmente, pautas secundárias ou mesmo excluídas do Direito Internacional dos Direitos Humanos (SANDERS, 2002: 2). Desde a elaboração da Carta Internacional dos Direitos Humanos, composta pela Declaração Universal de Direitos Humanos, $1948^{4}$, pelo PIDCP e pelo Pacto Internacional dos Direitos Econômicos Sociais e Culturais, 1966, foram promulgados os nove principais tratados de direitos humanos da Organização das Nações Unidas ${ }^{5}$ (ONU). Apesar dos avanços em temas como discriminação racial, mulheres, crianças e trabalhadores migrantes, nenhum deles faz referência à identidade de gênero e orientação sexual.

Pode-se dizer que as tentativas de introduzir o tema na arena internacional começaram com a Conferência Internacional sobre População e

e Degradantes; Convenção da ONU para Proteção de todos os Trabalhadores Migrantes e suas Famílias; Convenção dos Direitos da Criança; Convenção sobre Eliminação de Todas as Formas de Discriminação contra a Mulher; Convenção sobre o Direito das Pessoas com Deficiência; Convenção Internacional para Proteção de Todas as Pessoas contra o Desaparecimento Forçado. 
Desenvolvimento (Cairo), de 1994, frustrada pelo receio de alguns Estados, sob a influência da Santa Sé (CÔRREA, 2009: 26). Na Conferência Mundial sobre a Mulher (Pequim), de 1995, a orientação sexual e os direitos sexuais foram o cerne das discussões, não tendo sido, contudo, destacados no documento final. De maneira mais palpável, a orientação sexual e a identidade de gênero se inserem na agenda internacional no âmbito do $\mathrm{CDH}$, a partir de 2003, quando o Brasil ressaltou a necessidade de criação de uma resolução reconhecendo a discriminação em razão da orientação sexual e identidade de gênero - muito embora tenha retirado a proposta posteriormente. Finalmente, uma Declaração foi adotada pela Assembleia Geral em 2008, na qual trata da discriminação com base na orientação sexual (PÉREZ, 2014: 150-151; ROSEMAN e MILLER, 2011: 362).

Não obstante, é alarmante o avanço de forças conservadoras nas atuais negociações da agenda pós-2015, representado, sobretudo, pela Santa Sé e por países do mundo árabe (ROSEMAN e MILLER, 2011: 352). A adoção de um tratado de direitos humanos que verse sobre orientação sexual e identidade de gênero seria, portanto, uma pauta ainda sensível, dado que a elaboração de normas "ambiciosas" poderia gerar extrema oposição desses grupos, resultando no fracasso do instrumento.

Ainda assim, os nove principais tratados, assim como a DUDH, consagram o direito à igualdade e o princípio básico da não-discriminação, atualmente reconhecidos com pilares do Direito Internacional dos Direitos Humanos, ou mesmo como elementos integrantes do direito internacional consuetudinário (TRINDADE, 1999: 77).

A Declaração Universal dos Direitos Humanos, por exemplo, enuncia no art. I que "todas as pessoas nascem livres e iguais em dignidade e direitos" e prossegue no art. II, afirmando que “[...] toda pessoa tem capacidade para gozar os direitos e as liberdades estabelecidas na Declaração, sem distinção de qualquer espécie [...]".

Da mesma forma, o art. $2^{\circ}, \S 1$, do PIDCP determina o dever dos Estados de garantir todos os direitos previstos no Pacto a todos os indivíduos presentes em seu território "sem discriminação alguma [...] por motivo de raça, cor, sexo, língua, religião, opinião política ou de qualquer outra natureza, origem 
nacional ou social, situação econômica, nascimento ou qualquer outra situação".

$\mathrm{O}$ direito à igualdade formal é previsto no art. 26 do Pacto, afirmando: “todas as pessoas são iguais perante a lei e têm igual direito, sem discriminação alguma, a igual proteção da lei [...]”. O Comentário Geral n. 18 do Comitê de Direitos Humanos, a respeito do direito à igualdade, entende que "a não discriminação, assim como a igualdade perante a lei e a igual proteção da lei sem nenhuma discriminação, constituem um princípio básico e geral, relacionado à proteção dos direitos humanos" (ONU, 1989: 1). É possível dizer, dessa forma, que o princípio da igualdade e da nãodiscriminação abrangem todos os direitos humanos consagrados em instrumentos internacionais de proteção.

\section{Discriminação baseada na orientação sexual}

O reconhecimento de relações de poder que geram opressão e dominação de grupos e indivíduos é necessário à compreensão do que seja um tratamento igualitário e não discriminatório (BRAGATO e ADAMATI, 2014: 92).

De modo geral, tem-se orientado no sentido de considerar discriminatória qualquer distinção sem legítimo propósito, justificativa objetiva e razoável, e que não possua relação de proporcionalidade entre meios empregados e os objetivos pretendidos (TRINDADE, 1999: 78).

Nessa direção estão as distinções baseadas na orientação sexual e identidade de gênero, pois, em que pese os tratados internacionais não obrigarem os Estados de maneira explícita a reconhecerem o direito à família e ao casamento homossexual, o princípio da não-discriminação estende a eles o dever de garantir que casais do mesmo sexo tenham os mesmos direitos e benefícios que casais heterossexuais, casados ou não.

Tradicionalmente, o direito à família foi associado ao matrimônio, sendo considerado o marco da unidade familiar (SOARES et al, 2008: 69). Na verdade, o sentimento de família era desconhecido até o século XVI, tendo surgido vigorosamente apenas no século XVII. Segundo Phelippe Ariès (2011: 143), os laços sanguíneos constituíam dois núcleos distintos e concêntricos: a família (mesnie), equivalente à unidade conjugal moderna, e a linhagem, que correspondia à descendência de um mesmo ancestral. Pelo menos entre a 
nobreza, haveria entre esses dois núcleos uma oposição, fortalecendo ou enfraquecendo uma a outra. Portanto, a família conjugal moderna seria apenas uma evolução que deu origem ao modelo de família patriarcal do século XIX.

Os tratados de direitos humanos do século XX não escapam a essa lógica, relacionando casamento e família. A exemplo disso, o Pacto Internacional dos Direitos Civis e Políticos reconhece o direito à família, protegendo o direito "ao homem e a mulher a contraírem matrimônio" 6 . Contudo, a definição de família é diversa, abrangente e dinâmica. Existem relações que não se enquadram no modelo nuclear de família, baseadas em vínculos biológicos ou não, que ultrapassam os limites das concepções jurídicas dos tratados (BUTLER, 2003: 221). Nesse sentido, na atual etapa de desenvolvimento do Direito Internacional dos Direitos Humanos, não se deve mais limitar o conceito de família ao casamento entre homem e mulher, pois os tratados de direitos humanos "são instrumentos vivos, que acompanham a evolução do tempo e do meio social" (TRINDADE, 1999: 53).

\footnotetext{
6 Art. 23 do Pacto Internacional dos Direitos Civis e Políticos.
}

\section{$\mathrm{O}$ direito à família no âmbito do $\mathrm{CDH}$}

Essa interpretação evolutiva encontra expressão, embora ainda de maneira incipiente, nas decisões do mecanismo quase-judicial de supervisão do PIDCP, o CDH. Em 1994, no Caso Toonen vs. Austrália, o Comitê considerou que os Estados são obrigados a proteger as pessoas de discriminação baseada na orientação sexual. (UNITED NATIONS, 1994: 3).

No Comentário Geral n. 19, o Comitê reconhece a existência de diversas formas de família, uma vez que não existe um conceito uniforme, mas sim variável. Contrasta com essa interpretação o entendimento do órgão no primeiro caso em que apreciou o direito ao casamento entre pessoas do mesmo sexo (UNITED NATIONS, 1990: 1). O Caso Joslin e outras vs. Nova Zelândia, de 2002, surge da demanda das requerentes pelo direito à licença de matrimônio. Joslin e Rowan mantinham um relacionamento lésbico desde 1988, vivendo juntas e tendo assumido a responsabilidade pelos filhos de casamentos anteriores. Em 1995 
solicitaram licença de matrimônio, requisição negada. Em circunstâncias semelhantes, Zelf e Pearl também tiveram sua demanda negada, tendo sido informadas pelo Diretor do Cartório de Registro Civil de que a Lei do Matrimônio só era aplicável à união entre homem e mulher (UNITED NATIONS, 2002: 3). As quatro solicitaram ao Tribunal Superior da Nova Zelândia a declaração de que casais de lésbicas teriam direito ao matrimônio, solicitação que foi negada, com base, inclusive, no artigo 23, parágrafo segundo do Pacto.

A Nova Zelândia alegou que, de acordo com as definições do Pacto, não considera as autoras e seus filhos famílias e que a impossibilidade de casais homossexuais contraírem matrimônio não deriva de trato discriminatório, mas da própria natureza da instituição "matrimônio" e o "consenso universal" na prática dos Estados respaldaria essa afirmação. O Comitê afirmou que o art. $23, \S 2^{\circ}$ é o único dispositivo do Pacto que utiliza os termos "homem e mulher" ao invés de termos genéricos como "todo ser humano" ou "toda pessoa", isso porque se tem reconhecido que o matrimônio é uma união entre unicamente um homem e uma mulher. Portanto, entendeu que não se pode afirmar que o Estado violou os artigos referidos em detrimento das autoras pelo "mero fato de negar matrimônio entre casais homossexuais" (UNITED NATIONS, 2002: 7-16).

No caso Young vs. Austrália (2003), o Edward Young manteve relacionamento homossexual com "C" durante 38 anos, período pelo qual the prestou cuidados até a data de sua morte, quando então solicitou pensão, na qualidade de pessoa a cargo de veterano. A comissão responsável denegou o pedido, afirmando que ele não se enquadraria nessa qualidade, uma vez que só poderia ser considerado "membro de um casal" pessoa que vivia com outra de sexo oposto (UNITED NATIONS, 2003: 3). No caso X vs. Colômbia, de 2007, o autor, que manteve relacionamento por 22 anos com seu companheiro, de quem dependia economicamente, teve negado o pedido de pensão pelo Fundo de Previsão Social do Congresso da República, sob a justificativa de que a legislação não permitiria a outorga de benefício a pessoas do mesmo sexo.

Em ambos os casos, o Comitê concluiu que as diferenças de tratamento na atribuição de benefícios de pensão 
para parceiros do mesmo sexo sem justificativa objetiva e razoável violavam o direito à igualdade, previsto no art. 26. Contudo, voto concorrente de dois membros do Comitê, em $X$ vs. Colômbia afirma que o dispositivo do art. 26 não se aplica a discriminação baseada em orientação sexual e mesmo que um casal homossexual não constitui família nos termos do Pacto e que, assim, não poderia reclamar prestações positivas do Estado fundadas no conceito de família composta por parceiros de sexos opostos (UNITED NATIONS, 2007, p. 13).

\section{Uma análise da jurisprudência do CDH à luz da teoria QUEER}

Pôde se perceber que, pelo menos até a década de 1990, o Direito Internacional dos Direitos Humanos encarou a heterossexualidade como sinônimo de ordem social, imprimindo legitimidade aos discursos que a sustentam enquanto tal. Essa legitimação é cristalizada e difundida a partir da naturalização das instituições que refletem o modelo patriarcal consolidado no século XVII, e expressa no Direito Internacional por meio de tratados e decisões seus mecanismos de supervisão. A teoria queer critica a abordagem das ciências sociais em relação às minorias sexuais $\mathrm{e}$ identitárias, estabelecendo-se como um contraponto à matriz essencialmente heterossexual e binária na qual atua o Direito.

$\mathrm{O}$ termo queer, que originalmente se referia ao que é bizarro, desviante ou anormal, foi ressignificado a partir de sua apropriação por gays e lésbicas, para designar práticas que não correspondem a norma sexual. A sexualidade é vista nos estudos queer como um mecanismo de estabelecimento de hierarquias baseadas no binarismo homo/heterossexual e os Estados vistos como mantenedores dessas estruturas de dominação. Dessa forma, a teoria queer permite repensar gênero, sexo e sexualidade independentemente da ótica binária e da matriz heterossexual da norma (JESUS, 2012: 42; BORILLO, 2011: 29).

Os Estados, principais sujeitos do Direito Internacional, são vistos como construções históricas que constituem famílias nos moldes heteropatriarcais e regulam as atividades sexuais tomandoas como as únicas "normais", a fim de perpetuar a reprodução social e as ideologias políticas. No plano 
internacional, esse discurso está marcadamente presente nos tratados, por instituírem o paradigma familiar tradicional como único merecedor da proteção e reconhecimento dos Estados, e por invisibilizarem modelos familiares que não se adequem a sua lógica funcional, relegando-os a ilegitimidade.

Nessa perspectiva, é necessário um exercício de desconstrução, isto é, demonstrar o jogo entre presença e ausência, demonstrar que o que parece natural, na verdade é histórico (MISKOLCI, 2009: 153-154). A teoria queer define-se, portanto, como um gesto crítico, desconstruindo categorias naturalizadas como sexo, gênero e sexualidade e permitindo, assim, avaliar a maneira como as normas e os mecanismos que as fundamentam são apresentados. Uma abordagem queer do Direito deve desnaturalizar a norma jurídica e os elementos históricos e jusfilosóficos que atuam na sua naturalização (BORILLO, 2011: 30).

Esse processo parece não ter sido completamente acompanhado pelo $\mathrm{CDH}$ na manifestação de suas decisões sobre direito à família. $\mathrm{O}$ mecanismo acatou alegações do Estado no caso Joslin, não reconhecendo casais lésbicos e seus filhos como entidades familiares. Ao

afirmar, no caso, que os termos "homem e mulher" têm sido consistente e uniformemente interpretados no sentido de reconhecer o matrimônio como a união entre unicamente pessoas de sexos opostos que desejem se casar, o Comitê reforça caráter binário $\mathrm{e}$ heteronormativo do Pacto. Note-se que o Comitê não esclarece quem estabeleceu esse entendimento "consistente e uniforme", quais os métodos interpretativos para chegar a ele ou mesmo quando começou (LANGFORD, 2017: 11).

Essa interpretação não apenas descreve ou regula uma prática social, mas busca através dela reescrever a realidade projetando uma "fantasia de normatividade" (BUTLER, 2003: 241). Sistematiza-se uma um discurso de poder através da norma, que eleva uma instituição dogmática acima de qualquer debate, criando-se então uma fantasia que foge da complexidade e pluralidade do que é real.

A deliberação contraria o próprio entendimento doutrinário do Comitê expresso no Comentário Geral n. 19, que reconhece a variabilidade do conceito de família, de maneira que não seria possível aplicar-lhe uma definição uniforme. Se a definição do conceito de 
família é variável, então o Comitê tem a liberdade de reconhecer o casamento entre pessoas do mesmo sexo (LANGFORD, 2017: 18). É lamentável que a decisão do órgão tenha limitado o direito ao matrimônio a união entre homem e mulher sem uma justificativa objetiva e razoável, senão a prática reiterada dos Estados em reconhecê-lo nesse sentido. A dissociação entre sexualidade e reprodução a partir da legalização de métodos contraceptivos desde a década de 1960, tem permitido repensá-las como duas dimensões juridicamente independentes, de modo que relações não reprodutivas, como as que existem entre pessoas do mesmo sexo, deveriam se tornar legítimas pela ótica do Direito. O binarismo aparece, portanto, como fundamento do sistema jurídico, legitimando uma hierarquia baseada na orientação sexual e identidade de gênero (BORILLO, 2011: 29-37).

Embora um acordo entre pessoas de sexos opostos seja constantemente invocado como condição sine qua non do matrimônio, como argumentado pela Nova Zelândia, é possível afirmar que o Direito nunca necessitou de fatos biológicos para composição de vínculos familiares (BORILLO, 2011: 29-43). A formação de vínculos se baseia em uma convenção, e não na mera subsunção de um fato natural. Dessa forma, é inválido afirmar que o não reconhecimento do direito ao matrimônio para casais homossexuais não deriva tratamento discriminatório, mas da própria natureza da instituição, uma vez o Direito não precisa da natureza para produzir vínculos familiares. De acordo com Borillo, com a fundação do Estado laico e a ruptura do Direito Civil com o Direito Canônico, a vida familiar passa a se basear não mais em uma instituição, e sim no contrato. O divórcio demonstra esse processo, uma vez que as partes podem desfazer o negócio matrimonial (2011: 47). A decisão do Comitê no caso, ao reiterar o caráter institucional do matrimônio com base na interpretação consistente e uniforme dos Estados - os próprios criadores de uma ordem jurídica que reforça o binarismo e a heteronormatividade - acaba por perpetuar tratamento discriminatório e ignora a evolução dos modelos familiares.

Nos casos supervenientes, entretanto, houve reconhecimento de igualdade entre casais homossexuais e heterossexuais não casados para concessão do benefício de pensão, tendo 
sido considerado violado o direito à igualdade. Essas decisões reconhecem de certa forma, como legítima a relação familiar entre casais homossexuais, embora os votos concorrentes representem ainda a presença de atores conservadores no sistema. Considerando os casos mais recentes, pode-se dizer que o Comitê tem feito uma interpretação evolutiva do Pacto à luz da nãodiscriminação, mas de maneira estrita. A escassa jurisprudência sobre tema e a parca fundamentação das decisões do mecanismo não permitiram até então uma articulação mais abrangente do conceito de família, de modo a compreender modelos compostos por casais do mesmo sexo, por exemplo.

Adicionalmente, é possível atribuir a ausência de uma redefiniçãa do conceito de família no âmbito do sistema global ao próprio domínio no qual recaem as demandas dos peticionários. Ou seja, as interpretações de caráter mais progressista têm sido vinculadas ao dispositivo do art. 26 do Pacto, cujo impacto recai indiretamente sobre aspectos do direito à família. No único caso em que se analisou a violação do art. 23, o direito à família de maneira autônoma, o Comitê limitou-se a uma interpretação literal do dispositivo, possivelmente na tentativa de se manter dentro de uma margem estreita de interpretação do PIDCP, buscando evitar denúncias do instrumento e preferenciando, assim, a coerência do sistema. Para Herrera Flores (2010, p. 54), o que se enfrenta é a ordenação e regulação de quem interpreta as decisões de poder, conformando as consciências dos submetidos a sua autoridade. A partir dessa perspectiva, não se pode pensar as decisões do mecanismo somente de uma perspectiva técnico-jurídica, mas igualmente através dos resultados aos quais conduzem, "desde a atribuição de significados aos fatos e às normas em função da cultura jurídica que predomina e os objetivos e valores dominantes" (HERRERA FLORES, 2010: 55). Nesse sentido, reconhecer outros arranjos familiares com base no art. 23 seria legitimar configurações de família que os próprios Estados reservam à ilegitimidade.

$$
\mathrm{O} \text { autor afirma que o Direito }
$$
privilegia indivíduos que pertencem à determinada classe em detrimento dos não privilegiados, mantendo ou aprofundando o distanciamento entre a proclamação formal da igualdade e o seu gozo efetivo (2010: 49). Assim, pode-se dizer que o discurso liberal- 
institucionalista não é adequado para compreender a conformação do Direito Internacional dos Direitos Humanos, dado que parte de um sujeito generalizado, afastado do contexto no qual vive. Cria-se um espaço onde indivíduos morais e racionais poderiam dialogar "idealmente", relegando o que proclama ser diverso ao campo da irracionalidade e produzindo uma ilusão de justiça pela mera existência de procedimentos (HERRERA FLORES, 2010: 50). Hellio Gallardo (2010: 55) compartilha dessa visão e crê que existe mesmo um abismo na seara dos direitos humanos entre o discurso que os afirma, a norma jurídica que os reconhece e o seu cumprimento efetivo. Isso porque a maneira pela qual o poder está constituído não favorece o empoderamento das capacidades humanas, ou a produção de "contextos de opção", dessa forma, os direitos humanos devem ser encarados como uma luta política permanente.

Além disso, cabe ressaltar que as petições por reconhecimento do Estado das relações não-heterossexuais constituem o Estado como detentor de um direito que na realidade deveria conferir independentemente da orientação sexual e identidade de gênero
(BUTLER, 2003: 225). O consentimento manifestado livremente e a ausência de danos a terceiros são (ou deveriam ser) os únicos aspectos da sexualidade que importam ao Estado, sendo todos os demais relativos apenas à vida privada (BORILLO, 2011: 33-4). Significa dizer que Estado continua a determinar o que é legítimo e ilegítimo em termos de sexualidade, a pessoas adultas numa relação consensual, não permitindo a plena autodeterminação sexual.

Diante desse contexto, o $\mathrm{CDH}$ ainda se revela um mecanismo incerto no processo de desconstrução do tradicional direito à família. As decisões até agora não permitem traçar um padrão bem definido de posicionamento do órgão diante do reconhecimento de arranjos familiares que escapam à lógica binária e heteronormativa instituída por seu próprio tratado-chave, mas os últimos casos sinalizam para adoção de uma interpretação evolutiva que tende a reconhecer a dinamicidade e pluralidade das formas de constituir vínculos familiares.

\section{Considerações Finais}

Como observado, a orientação sexual e a identidade de gênero eram 
pautas tradicionalmente excluídas do Direito Internacional dos Direitos Humanos, tendo sido timidamente inseridas na agenda internacional a partir da década de 1990. Consequentemente, demandas do direito das famílias LGBT, como direito ao matrimônio ou direito ao benefício de pensão não eram efetivamente discutidas em mecanismos internacionais de supervisão de tratados. $\mathrm{Na}$ verdade, a própria formação dos tratados de direitos humanos e a institucionalização de seus procedimentos de supervisão não fogem as dinâmicas de poder que constituem sujeitos generalizados, considerando que a invisibilização do que manifesta ser plural e diverso relega os sujeitos que assim se definem ao campo da irracionalidade e, com efeito, suas formas de constituir família, à ilegitimidade.

Uma abordagem queer do Direito permite repensar a matriz binária e heteronormativa dos tratados, conduzindo ao processo de desconstrução do molde tradicional de família, frequentemente tomado como único arranjo digno de amparo $\mathrm{e}$ reconhecimento jurídico. Nessa perspectiva, as decisões do Comitê de Direitos Humanos da ONU ainda revelam apego a essa concepção tradicional, utilizando-se de uma interpretação literal do Pacto, que ignora a evolução dos contextos sociais e dos modos de constituir vínculos familiares. Em contrapartida, as decisões mais recentes parecem indicar que $\mathrm{o}$ mecanismo quase-judicial tem realizado uma interpretação evolutiva do tratado em relação a casais hetero $\mathrm{e}$ homossexuais não casados, de modo a constituir espaços de empoderamento queer, a partir do reconhecimento da igualdade entre eles.

Além disso, dados o escasso número de casos até então decididos pelo Comitê e a limitada fundação das deliberações, não foi possível delimitar um padrão bem definido de interpretação do órgão sobre a matéria. Constatou-se, contudo, que as decisões mais progressistas são, em geral, vinculadas ao direito à igualdade (art. 26), cujos reflexos sobre o direito das famílias é significativo, em detrimento de uma consideração autônoma sobre o direito à família (art. 23). Dessa forma, acreditase que paulatinamente o CDH contribui, de forma tímida, mas mesmo assim progressiva, no reconhecimento ao direito à família LGBT. 


\section{REFERÊNCIAS}

ARIÈS, Phelippe. História social da criança e da família, $2^{\mathrm{a}}$ ed. Rio de Janeiro: LTC, 2011.

BORILLO, Daniel. Por una teoria queer del Derecho de las personas y de las famílias. Direito, Estado e Sociedade, n.39, jul/dez 2011. p. 27 a 51.

BRAGATO, Fernanda Frizzo, ADAMATTI, Bianka. Igualdade, não discriminação e direitos humanos: São legítimos os tratamentos diferenciados? Revista de Informação Legislativa, v. 51, n. 204, p. 91-108, out./dez. 2014.

BUTLER, Judith. O parentesco é sempre tido como heterossexual? Cadernos Pagu (21), Campinas, 2003, p.219-260.

DIAS, Maria Berenice. Manual de Direito das famílias. São Paulo: Revista dos Tribunais, 2016.

GALLARDO, Helio. "Derechos Discriminados y Olvidados". In: RÚBIO, David Sanchez et al (Orgs.) Direitos Humanos e globalização., $2^{\mathrm{a}}$ ed. Porto Alegre: EDIPUCRS, 2010, pp. 55-71.
HERRERA FLORES, Joaquín. Os direitos humanos no contexto da globalização: três precisões conceituais. Lugar comum n²5-26, Rio de Janeiro, pp. 39-71. mai-dez. 2008.

JABRI, Vivienne. "Mobilising Queer Theory for a Materialist Understanding of Space and the International". In: (Im)possibly Queer International Feminisms, 2nd Annual Conference, International Feminist Journal of Politics. 2013

JESUS, Diego Santos Vieira. O mundo fora do armário: teoria queer e Relações Internacionais. Revista Ártemis, Vol. XVII n $^{\circ} 1$; jan-jun, 2014. pp. 41-50.

LANGFORD, Malcom. "Revisiting Joslin $v$ New Zealand: Same-Sex Marriage in Polarised Times". In: BREMS, Eva, DESMET, Ellen (Orgs.). Integrated Human Rights in Practic Rewriting Human Rights Decisions, 2017.

MELLO, Celso D. de Albuquerque. Curso de Direito Internacional Público. $15^{\mathrm{a}}$ Ed. Rio de Janeiro: Renovar, 2004. 
MISKOLCI, Richard. A Teoria Queer e a Sociologia: o desafio de uma analítica da normalização. Sociologias, Porto Alegre, ano 11, no 21, jan./jun. 2009, p. 150-182.

NARAYAN, Pratima. Somewhere over the rainbow...internacional human rights protection for sexual minorities in the new milennium. Boston University Internacional Law Journal, vol. 24:313, 2006, pp. 313-348.

PÉREZ, Gloria Careaga. A proteção dos direitos LGBTI, um panorama incerto. Revista Internacional de Direitos Humanos - Sur, vol. 11, n. 20, jun./dez. 2014, pp. 146-153.

RAMOS, André de Carvalho. Processo internacional de direitos humanos. São Paulo: Saraiva, 2013.

ROSEMAN, Mindy Jane, MILLER, Alice. Normalizing sex and its discontents: establishing sexual rights in International Law. Harvard Journal of Law \& Gender, Vol. 34, Summer 2011, pp. 313-275.

SANDERS, Douglas. Human rights and sexual orientation in international law.
International Journal of Public Administration, 25(1), February 2002, pp. 13-44.

TRINDADE, Antônio Augusto Cançado. Tratado de direito internacional dos direitos humanos, vol.2 Porto Alegre: AS Fabris, 1999.

SOARES, Bruno Martins et al. O reconhecimento das uniões homo afetivas pelo direito brasileiro: contribuições do direito internacional dos direitos humanos. Revista Jurídica, n. 4, dez, pp. 65-79, 2008.

UNITED NATIONS. Human Rights Committee. General Comment $\mathbf{n}^{\mathbf{0}} 18$. 1989.

. Human Rights Committee.

General Comment no . 19. 1990.

Joslin et al v. New Zeland.

Communication $\mathrm{N}^{\circ}$ 902/1999. 2002.

Toonen v. Australia.

Communication $\mathrm{N}^{\mathrm{o}} 488 / 1992.1994$.

Young v. Australia.

Communication $N^{\circ}$ 941/2000. 2003. 
X. v. Colombia. Communication

$\mathrm{N}^{\circ} 1361 / 2005.2007$. 